\title{
Ultrasound Assisted Liposculpture - UAL: A Simplified Safe Body Sculpturing and Aesthetic Beautification Technique
}

\author{
Nikolay P. Serdev \\ Medical Centre "Aesthetic surgery, Aesthetic medicine" \\ Head, International University Program in Cosmetic Surgery, \\ New Bulgarian University, Sofia \\ Bulgaria
}

\section{Introduction}

The use of ultrasound for cosmetic surgery has been introduced since the late 1980's, and the technique and equipment have been improved during the years.

Authors experience on 1300 patients since 1994 has proven that the ultrasound assisted liposculpture - UAL is a simplified safe procedure. UAL delivers ultrasonic energy directly to deep fat deposits through very tiny incisions in the skin. This technique enhances the current procedure in liposuction by adding ultrasonic waves to break down the magnified and giant fat cells in the deep fat deposits, preserving normal size microscopic fat cells in the superficial subdermal fat layer, which enables smooth results with UAL. This technique shortens the total multi-area operation time to about one hour or less and avoids possible mechanical damage to surrounding tissues.

We use the ultrasound assisted liposculpture with tumescent infiltration and UAL thin probes to precise location of deep fat deposits. UAL should not be used as a dry method. Blood vessels, muscle cells, and other small bodily structures remain unharmed by the selected ultrasound wave. Once the ultrasound liquefies the targeted fat area, we use a very gentle suction internally to remove the fat. UAL is particularly useful for areas affected by scar tissue, large areas, or areas with dense fields of fat, but for us UAL is the best method for very fine body reshaping in skinny patients seeking for beautification. It is also popular in the treatment of gynecomastia. The UAL requires more specialized equipment.

In the recent years the Vibration Amplification of Sound Energy at Resonance System[14] (VASER) became another method of liposuction using ultrasound and we use it with same atraumatic and aesthetic success in our practice in the last 3 years.

Important aspects of patient selection, markings, surgical technique, and postoperative care are outlined.

\section{History}

In 1921, Charles Dujarier, in France, attempted to remove subcutaneous fat using a uterine curette on a dancer's calves and knees. A tragic result occurred due to injury of the femoral 
artery leading to amputation of one of the dancer's legs. In 1964, Schrudde extracted fat from the lower leg through a small incision with a curette. Hematomas and seromas resulted from this technique. Pitanguy favored an to remove excess thigh adiposities. Significant noticeable incisions diminished the popularity of en bloc removal of both fat and skin. Arpad and Giorgio Fischer published first their results from aspiration of fat in 1976. Working in Rome, they developed a blunt hollow cannula equipped with suction. Some of their early cannulas also contained a cutting blade within them. They also developed the technique of crisscross tunnel formation from multiple incision sites [1,2]. Fewer complications such as hematomas and seromas were seen than with sharp curettage. In 1977, Pierre Fournier, working in Paris, showed an early interest in the Fischers' liposculpture technique. Later Fournier subsequently became a world leader in liposuction and fat transplantation, eventually recognizing the benefits of tumescent anesthesia and contributing greatly to teaching syringe liposuction to surgeons throughout the world [915]. Illouz [9-10] felt the solution was a "dissecting hydrotomy" which would facilitate the removal of fat and reduce trauma with less bleeding. Illouz was responsible for creating worldwide publicity for the new procedure. Julius Newman, an otolaryngologist and cosmetic surgeon, and his associate Richard Dolsky, a plastic surgeon, taught the first American course on liposuction in Philadelphia in 1982. The first live surgery workshop was held in Hollywood, California, in June 1983 under the direction of the American Society of Cosmetic Surgeons and the American Society of Liposuction Surgery. Newman first used the term "Lipo Suction" and established the American Society of Liposuction Surgery [53]. Initially, large cannulas were employed for liposuction, some up to $1 \mathrm{~cm}$ in diameter. In 1987, Jeffery Klein developed the tumescent technique, allowing nearly bloodless liposuction using only local anesthesia [3]. This innovation involved infiltration of a dilute solution of lidocaine with epinephrine to allow more extensive liposuction totally by local anesthesia, significantly reducing bleeding [16]. To date, there have been few complications and no fatalities when the tumescent anesthesia technique is employed as a local anesthetic approach without excess intravenous fluids or general anesthesia [29]. After having been used for many years in other medical specialties, selective ultrasound waves have been introduced to simplify and facilitate the liposuction, reducing the blood loss by first liquefying fat. In 1987, Scuderi et al. offered the use of ultrasound as an emulsifying modality for adipose tissue. Then Zochhi in 1988 first presented the ultrasonic liposculpturing, built on the Scuderri's concepts $[7,8]$, as a totally new technique, based on the surgical use of the ultrasound energy that allows for the selective destruction of excess adipose tissue, or rather of it's fluid fraction [18, 19, 23]. It was introduced to be combined with infiltration $[3,6,8,16]$. UAL is effective because of its effect not only on fatty tissue but also on loosening the cell-to-cell structures, allowing easy removal of adipose cells [4]. Later external ultrasound (Hydrolipoclasis Ultrasound) was introduced for smaller fat amounts without or with liposuction [23, 25, 51, 52]. The firstly undue fear [20, 23, 39] of heat was later used in subsequent techniques like laser assisted liposuction [21]. So, in the recent years, lasers introduced the thermal lipolysis as a comparison to traditional techniques.

\section{UAL}

UAL is a type of liposuction that is primarily used for fat removal in hard-to-treat areas such as the chin, neck, cheeks, knees, calves, and ankles. It is best indicated in tumescent liposculpture for patients who require more precise body contouring. 
Few studies conducted to compare classical liposuction with UAL[40, 46.]. The studies were done comparing ipsilateral traditional lipoplasty with contralateral ultrasound assisted lipoplasty on one or more body area. The ultrasound liquefies fat thus the aspirate is less bloody and contained more fat than tradition liposuction aspirate. Skin tightening and weight loss cannot be compared to traditional liposuction that is more traumatic. Classic liposuction does not achieve metabolic benefits of weight loss. [47] "UAL is not a replacement for suctionassisted lipoplasty - SAL; it is an extension of this technique."[40] The advantages of UAL are selective destruction of fat cells, the possibility of skin tightening of treated areas, and a reduction of physical strain on the surgeon $[8,28]$. UAL uses high-frequency sound waves to liquefy fat beneath the skin surface before removing it with a gentle suction. Tumescent liposuction and traditional liposuction cannot liquefy fat cells, and this makes the fat more difficult to remove. There is less surgeon fatigue, allowing the surgeon to focus on true sculpting in body contouring and less tissue trauma.[28] UAL is also successful in breast surgery $[48,49]$ and as a very superficial ultrasound-assisted lipoplasty for the treatment of axillary osmidrosis.[50] UAL allows the trabecular system and elastic skin to retract, but the degree of skin tightening following UAL depends on the age and quality of skin.

Ultrasound waves in the infiltrated tissue cause fat tissue destruction via:

1. Selective destruction of single adipose tissue fluid - UAL uses chemo-physical effect of strong sound-waves in a fluid, formulated by Alfred Loomis, 1927 [8],

2. Micromechanical effect - Ultrasound displaces intracellular molecules, breakups up chromosome, and conglomeration of molecules caused by the breakup of intermolecular bridges, leading to cessation of DNA duplication, modification of the proteins spatial structure, formation of free radicals, denaturation of the cellular membrane components and electrochemical modifications of the cellular surface ${ }^{[18,19,21]}$;

3. Cavitation phenomenon - strong cellular fragmentation and lipolytic effect;

4. Thermal effect if the techniques is properly used, this will be minimized and won't create collateral damages[21, 24,25];

5. Preservation of vascular and nervous structures [21, 24];

6. Reduction of blood loss. [18, 26-28]

\subsection{Alternatives}

Many alternatives to UAL exist. These include diet and exercising, other liposuction techniques, excision techniques, removal of lipomas, breast reduction etc. External Ultrasonic Hydrolipoclasis[21, 24] and external UAL have been used for smaller amounts of fat, but external UAL has not provided the promised ideal of fat dissolution without surgery (suction).[51,52]

\section{Patients selection}

Since 1994, we performed Ultrasound Assisted Liposculpture(UAL) on 1300 patients targeting a total of 5200 body areas with very good aesthetic results, short downtime, and a very low level of blood loss and bruising.

The author selected patients with localized excess adipose tissue in specific areas, even if the patient is at or below his or her ideal weight. Overweight patients may also benefit, but generalized obesity was excluded by author as is not in the scope of beautification [14, 41, 42]. The best results were achieved on healthy patients with good skin elasticity and localized deposits of excessive fat.[14] If patients have more fat than can be removed safely in one 
operative setting, a second session or more was planned. Ultrasonic liposuction appears to be most useful in treating larger or more fibrous areas thus reducing blood loss and post operative pain.

\subsection{Indications}

We used UAL for the following indications: aesthetic beautification, removal of unwanted fat deposits and aesthetic body contouring, facial and double chin contouring, gynecomastia and breast reduction, correction of irregularities, calves elongation by reduction and change of the position of the inner knee fat, elongation of the thighs by reduction and reshaping fat surround the buttocks, removal of fat in very fine areas like ankles, calves, face, and total body contouring.

We did not use UAL for the treatment of general obesity (isolated areas can be treated in multiple sessions). UAL cannot be substitute of a balanced exercise and diet. However, it may help patients to remove areas not affected by diet and fitness or exercises. We also did not use UAL for the treatment of dimpled, uneven superficial fat surfaces of cellulite. UAL can be also used in bodybuilders to create the abdominal "six packs" which is increasing in demand, but patients have to be informed not to stop hard exercise as this will cause accumulation of visceral fat leading to abdominal "turtle shell" appearance.

\section{Method}

The author's UAL technique was performed on an outpatient basis under local tumescent anesthesia and i.v. monitored sedation. Dry technique was not used. In order of achieving the desired cosmetic aesthetic results, the author recommends to avoid using UAL superficially. The author's technique maintains the surface untouched "taboo area", to avoid surface irregularities.

\subsection{Anesthesia}

Our experience is very good when using local anesthesia - Klein's tumescent technique $[3,4,6]$ combined with additional IV monitored anesthesia: mild sedation, iv analgesia with opioids and NSAIDs.

The recommended maximum safe dose of lidocaine (when used with epinephrine) is 35 $\mathrm{mg} / \mathrm{kg}$ based on Klein's study [6]. However, lidocaine doses up to $64 \mathrm{mg} / \mathrm{kg}$ have been safely used by some authors.[16, 25-28]

Epinephrine is a critical component of the wetting solution. It has a vasoconstrictive effect that minimizes blood loss and delays the absorption of lidocaine. The total epinephrine dosage used in wetting solutions range from 1:200,000 to 1:1,000,000 [5].

Local anesthesia with sedation is a reasonable option especially in the ambulatory surgery and in procedures of shorter duration. The advantage of local tumescent anesthesia is shorter recovery period, decreased postoperative hypoxemia and lower rates of postoperative nausea and vomiting [29].

Infiltration has to be properly and uniformly distributed in the fat deposit in order to obtain smooth results after the suction!

\subsection{Short time ultrasonic application}

After infiltration of the areas to be treated, we introduce a selected ultrasonic probe into the specific body area and use the properly selected power no more than 4-6 minutes per ca. 200 
cc adipose tissue.[28] The probe should be moved slowly uniformly all over the fat deposit. Once the feel of fat softening (liquefication) is achieved we stop. We never use hollow ultrasonic probes for ultrasound action and suction at the same time!

\subsection{Anatomic approach}

Ultrasound treatment should be applied onto the deep adipose tissue, below the superficial subdermal fascia. We never apply the ultrasound superficially as proposed for superficial classic liposuction![30-32] Ultrasound waves are effective for unstable increased in size and giant cells alone (in the deep localized fat deposits) and do not affect the normal microscopic cells in the superficial subdermal layer. Proper selection of both ultrasound power and probes is important and manufacturers guidelines should be followed. With the VASER ${ }^{\circledR}$ we never exceed $70 \%$ power. Application of inappropriate power of ultrasound and or the use of improper probes could be too damaging to tissue!

\subsection{Low aspiration}

After achieving the liquefication of fat, we use low-pressure suction of the liquid fat, which is easily done, in a manner of a violin play. Histological evaluations revealed that these parameters were associated with minimal effect on connective tissues and blood vessels.[33] Longer application times are associated with disruption of collagen and elastin structures. The lower suction of fluid could be compared to suction applied by drinking fresh juice with a straw, i.e. there is only a minimal trauma to the tissue, resulting in nearly no blood loss. It is advisable to end liposuction once the aspirate changes in color from yellow to pinkish red! It is important to create smooth transition between the area treated and the surrounding areas! At this moment we have to make sure that all deep fat is equally removed and the superficial fat layer is similar in thickness to the surrounding untreated areas.

The average blood loss is no more than $100-250 \mathrm{ml}$ during the whole procedure even if multi-areas are addressed in one session. We have never had a case requiring blood transfusion.

\subsection{Number of treated areas per session}

The number of treated areas per session is limited on the first place by the maximum lidocaine dose allowed based on the patient's weight in kilos. The lidocaine dose ranges from 45 to $60 \mathrm{mg} / \mathrm{kg}$ without any serious lidocaine toxicity. We use the dosage below 35 $\mathrm{mg} / \mathrm{kg}$ as "exceedingly safe" [6] and count the number of possible areas we can infiltrate with this amount of tumescent solution. Independently of the low blood loss, the patient's health and status evaluation at the time of operation will dictate the number of areas treated and maximum lidocaine dose used.

\subsection{Pre operative consultation and evaluation}

Initial consultation is scheduled to clinically assess the health status of the patient. This includes history, physical exam, and a psychological evaluation. Any health problem should be referred to a specialist and treated adequately. No patients will be operated on unless he or she obtains a medical clearance from a specialist. Pre-existing conditions should be checked and brought under control before UAL. This includes: history of heart problems, high blood pressure, diabetes, allergic reactions to medications, pulmonary problems, smoking, alcohol, drug use or abuse. If needed (in cases of presumable allergic reactions, 
history of uncontrolled diabetics etc.), we request the corresponding consultants to be present during surgery, and to manage the patient's medical condition peri-operatively. An anesthesiologist is always present in the operating theatre during surgery. In all our clinical cases we used IV monitored sedation and analgesia in addition to the local tumescent anesthesia.

Preoperative blood and urine testing should include basic blood chemistry evaluations (CBC, prothrombin time/activated partial thromboplastin time, bleeding time and general chemistry) to screen for any renal, hematologic, or hepatic disease before the procedure. ECG is needed in elderly and if indicated in younger patients. The results should be interpreted together with the anesthetist and if necessary with consultants. Health status should be checked again before surgery. Patients are asked one more time about using contraindicated medications and drugs. Before the procedure, no anticoagulants, antiplatelet, hormonal and NSAIDs medications should be taken for two weeks before and after surgery. Fasting is required for four hours before the operation to prevent from regurgitation and aspiration, which can provoke postoperative bronchopneumonia. Smoking should be avoided, as nicotine interferes with circulation and can result in hypoxemia and loss of tissue.[16, 20,38]

In general, a good candidate for UAL (as well as other liposuction techniques) is a person with an average or slightly above average weight, in good health, with a localized area of fat that does not respond well to diet and exercise. Slim models are best candidates in our hands, because the UAL does not affect the normal size fat cells in the superficial subdermal fat layer. After surgery the even subdermal fat layer will tag along the usually aesthetic form of the muscular and skeletal frame. Patients with superficial fat layer affected by lipodystrophy are not good candidates for UAL.

Before surgery, patient's problematic areas and desired result will be discussed one more time. Patients must understand fully the pre-operative preparations, the procedure, the post-operative care and predicted aesthetic results, enhancing appearance and self-esteem. Patients who are not motivated and psychologically unstable are declined. After full understanding the risks and possible complications, the informed consent form and permission forms for photography should be fulfilled and signed.

Similar to traditional liposuction, the skin is marked in standing position to indicate the areas from which the fat will be removed. We mark only outer borders of the fat deposits as well as depression borders, keeping in mind that in horizontal position, the deposits will move in cephalic direction and downwards with minimum $2-5 \mathrm{~cm}$. Too much marking is false, because fat deposits change their position from standing into horizontal position. Marking of highest bulges is also false in our experience. They will change much, due to gravity vectors. Photography in different positions and light angles are necessary, to visualize and document the status and irregularities, preoperatively.

In the operating theatre, a disinfection solution, such as Betadine, is applied to the relevant areas. The first step in the ultrasonic liposuction procedure is the uniform infiltration of tumescent fluid into the area being treated. The tumescent local anesthesia technique allows the patient to move intraoperatively into the exact position, needed for our work to treat and remove fat without difficulty. Lidocaine toxicity must be properly considered.

Patients should be monitored during the procedure. The patient should have an IV fluid line; the fluid balance must be kept intact. There are also monitoring devices in use to keep track of the blood pressure, heart rate, and blood oxygen level. 
The surgeon should have a full understanding of the features of the ultrasound device used, its proper application of selective ultrasonic destruction of fat, as well the correct power and probes selection.

After the uniform tumescent infiltration in the selected level and area is done, the proper ultrasound power and ultrasonic probe are chosen and then the probe is inserted through small 11 blade incisions, each about 2-3 mm. The introduction of infiltration cannulas, ultrasonic probes, and aspiration cannulas through the skin and the superficial fat layer are done in a perpendicular direction through the superficial fat layer and then the direction is changed, in order to prevent the superficial layer from damage and aspiration. We have proven that the temperature on the probe lateral walls using the prescribed energy stays below 37 degrees Cs. We have never experienced any change in the skin temperature, higher than 37 degrees Celsius. The temperature at the ultrasonic probe lateral wall has been found below 37 degrees Cs in our first hundred clinical cases and all next regular tests. These findings allowed us to safely use the ultrasonic probes without skin protectors. It allowed us to widen the frontiers of ultrasound assisted liposculpture and we were able to use the UAL in very tiny areas like ankles, calfs, face etc. without leaving visible scars. Our clinical experience has proven the probe temperature safety at the skin level in all our clinical cases.

After introducing of the probe to the respective deep fat deposit, the probe is maneuvered in a crisscross pattern all around the deposit, while sound waves generate negative pressure, causing nearly the whole amount of fat cells in the deposit to implode, collapse, and liquefy. The huge difference with traditional and some other liposuction methods is that the wave is active some centimeters from the probe tip in front and lateral and destroys the fat three dimensionally, while the suction cannula is creating tunnels with unaffected fat between tunnels. Comparisons between equal aspirates in traditional liposuction and UAL are fake, because the UAL destroys more fat than aspirated and has a prolonged effect of fat desorption. In all our patients we have observed lose of volume not only in the area of procedure but also from all around the body during the first six months following the procedure (See Fugures). The slimming effect after UAL became one of the positive side effects in our practice along with skin tightening! Patients for UAL should not be asked to slim before the procedure because diet reduces body response to stress and has negative effects like skin drooping and decreases by number the indications for liposuction and increases indications for excision surgery.

\subsection{Areas of the body treated by UAL}

Ultrasound can help break up tough fibrotic fat in different areas of the body, like face, ankles, calves etc. that are difficult to remove with traditional liposuction. Fat in the leg are ideal for UAL because of the elongation effects and beautification achieved by this technique. Ultrasonic liposculpture is recommended in areas that require precision. Tumescent UAL is among the safest and most effective techniques in chin, cheeks and jowls, ankles. The areas that we treated with UAL include the following:

a. Face and neck: Cheeks and submental (double chin)

b. The abdomen is one of the most common areas requested by both men and women. It is divided with the fascia into lower and upper parts with different anatomical fat structure. In the lower part, we have to leave a very thin superficial layer of fat. The peri-umbilical fat has a "croissant" shape. Anatomically this is a separate superficial fat structure, divided from the rest of abdominal fat by a fascia and should be treated 
separately. Upper abdomen requires skilled contouring to preserve normal concavities and six packs in body builders.

c. Tumescent UAL of upper arms gives the best cosmetic result of skin tightening.

d. UAL in female breasts as well as in localized "bra-fat" provides aesthetic improvement with usually a moderate breast lift, due to reduced tissue weight and good skin retraction.

e. Treatment of pseudogynecomastia due to fat accumulation is one of the most frequent indications in males together with abdominal, flank and pubic fat, as well as double chin.

f. The area where smooth results are extremely difficult to obtain is the anterior thigh, where maximal volume reduction easily produces irregularities.

g. UAL of the outer and inner thighs, and inner knee UAL provides the most significant aesthetic improvement of the leg silhouette, with a visible elongation and straightening of lower extremities and body proportions (Fig. 1, 2, 3, 4).

h. Buttocks UAL can achieve results with a pleasing lifting, roundness and reduction. It gives elongation of the legs and better proportion to body (Fig. 4.).

i. We obtained a dramatic aesthetic improvement in the ankles and crus. The localized fat in these areas is genetically predetermined, and is resistant to diet and exercise.

j. Crus localized fats are mostly reduced from laterally and often need fat transfer to the inner part.

k. Areas that have been previously treated with liposuction and where is need of further contouring, respond very well to UAL
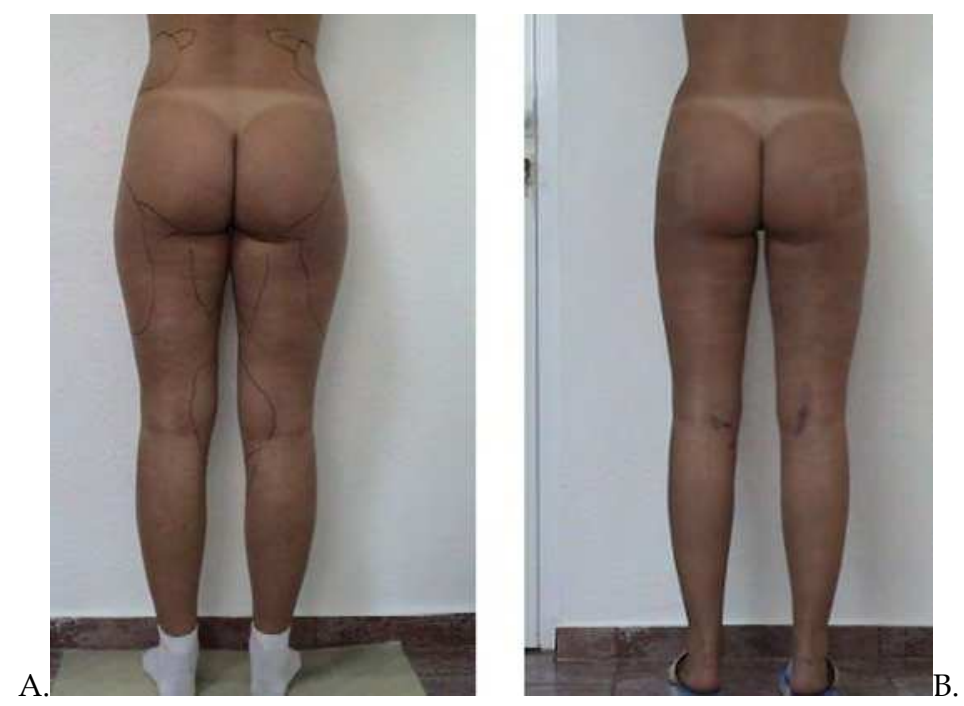

Fig. 1. A. Before, B. Result on day one after UAL of flanks, lower buttocks, outer and inner thighs, inner knees. Good effect of crus and leg elongation. Great loss of fat amount and minimal bruising. 

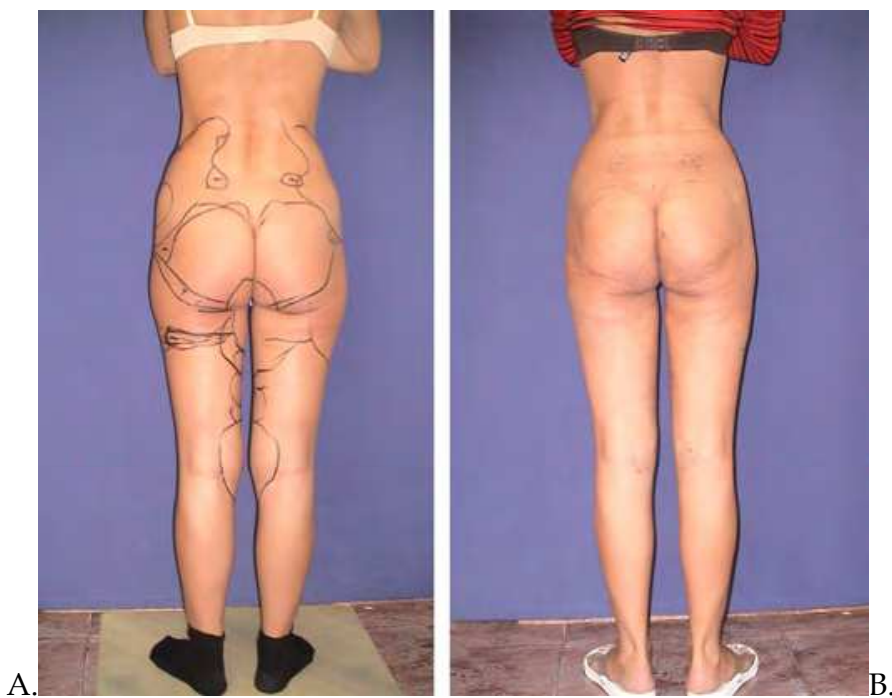

Fig. 2. A. Before, B. Day one after UAL of flanks, lower buttocks, outer thighs, inner thighs and inner knees and buttock lift by Serdev suture technique. Surgical markings from the previous day are still visible. Note the relative elongation of the crus and legs. Buttocks look smaller, rounded and at a higher position due to body proportions changes.
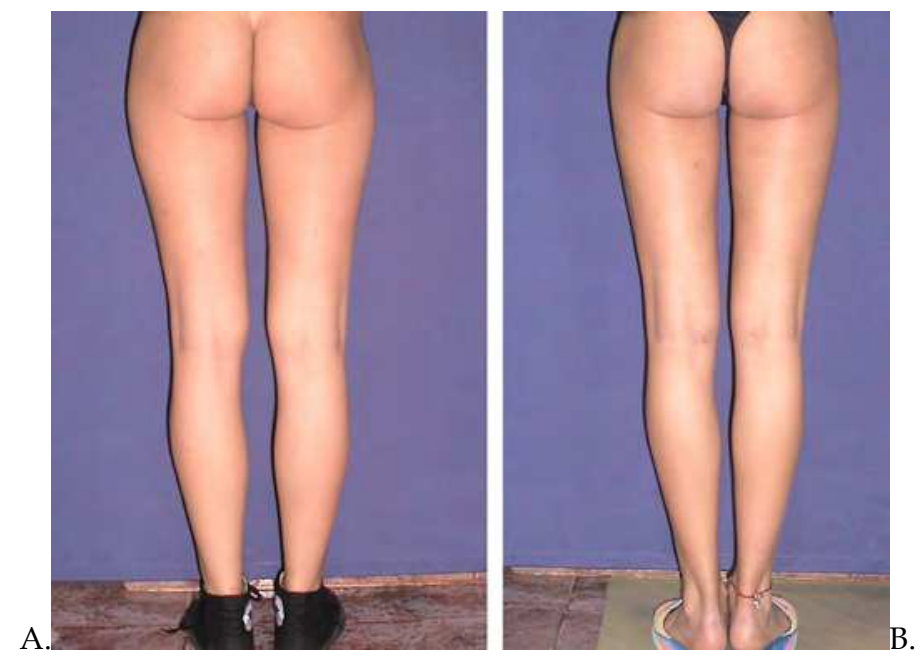

Fig. 3. A. Before, B. After UAL of lower buttocks, outer thighs, inner thighs and inner knees. Result of straitening and legs elongation of a skinny model. Important volume reduction where needed, higher knee position for crus elongation along with smooth results and no surface irregularities. 


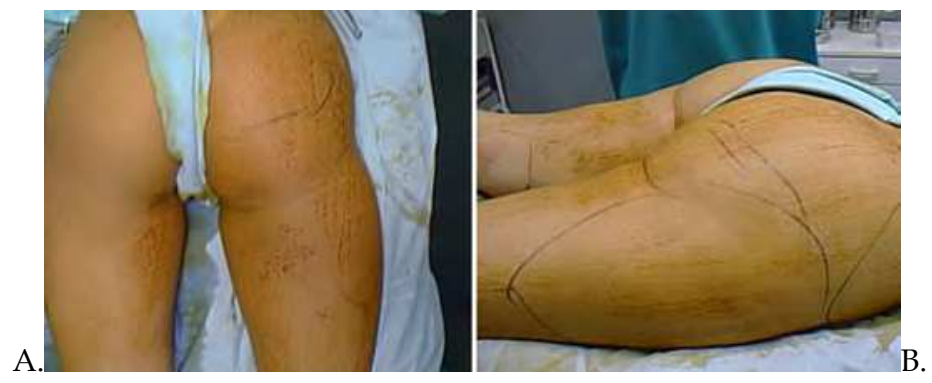

Fig. 4. A. and B. Left buttock reduced using UAL. Right buttock still not treated. Effect of buttock's lift on the left side in different patients using UAL. Visible lift of 3-5 cm of the infragluteal sulcus.

\subsection{No sutures}

Since the incisions are small, we leave the incisions open, to drain the tumescent fluid. Drainage of the fluid allows the incisions to heal more quickly. Some surgeons suture them partially, leaving space for the fluid to drain out $[34,35,36]$. While the fluid is draining, dressings need to be changed daily. Patients take a daily shower in the clinic for about 7 days, and incisions are disinfected. It is important to open and drain the wounds for few days post-op as they are very tiny and could be occluded.

\subsection{Outpatients procedure}

As patients do not receive general anesthesia, after a time for stabilization, usually they are ambulatrory and can go home the same day, although they need someone else to drive them and stay with them in the first 24 hours.

\subsection{Recovery}

Depending on the extent of the UAL procedure, patients are generally able to return to work after two to three days. In the first 48 hours, pain is controlled by over the counter meds or by prescription medications, usually. Bruising dissipates in few days to weeks. Swelling subsides with time. Normal activities can be resumed after 2-3 days. The result is visible even on the first day post-op (Fig. 1, 2, 8) but will be much evident after six months when skin tightening and resolution of edema are attained (Fig. 5, 6,8). Skin tightening, which is a positive side effect of UAL goes on for up to 6 months after surgery (Fig. 5, 6, 7). Weight loss in the first 6 months to normal is another very favorite side effect after UAL (Fig. 5, 6). The destructed and suctioned fat cells are permanently lost, however patients have to maintain a proper balance between calories intake and exercise regimen. Any positive intake balance causes the fat cells all around the body to enlarge.

\subsection{Postoperative care}

We administer antibiotics for 7-10 days. Patients apply elastic compression garments to areas that we have treated to prevent seromas, minimize bruising and decrease soreness in these areas. Patients are informed about postoperative leakage of tumescent fluid from incision sites for up to several days. Patients should be reassured that such leakage is common. 

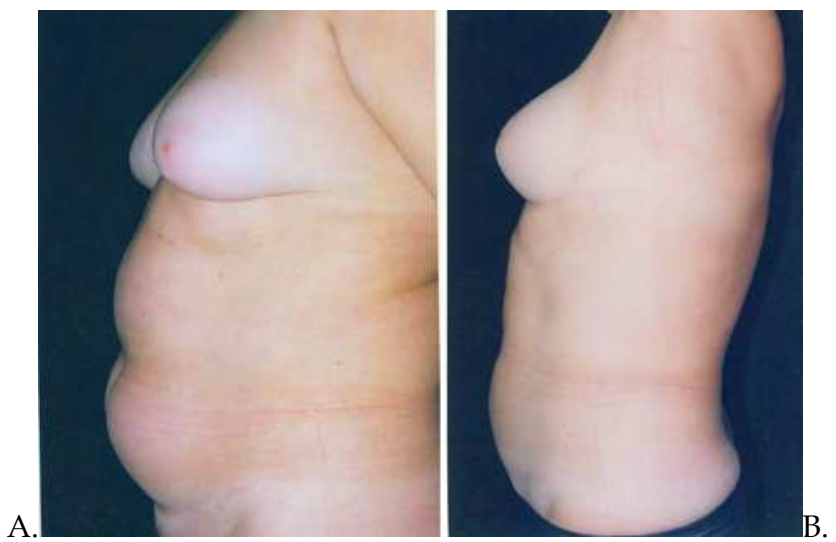

Fig. 5. A. Before. A $90 \mathrm{~kg}$ female patient, B. Result 6 months after UAL of abdomen and flanks and removal of 2 liters of aspirate. The patient has lost $40 \mathrm{~kg}$. Very good skin retraction.

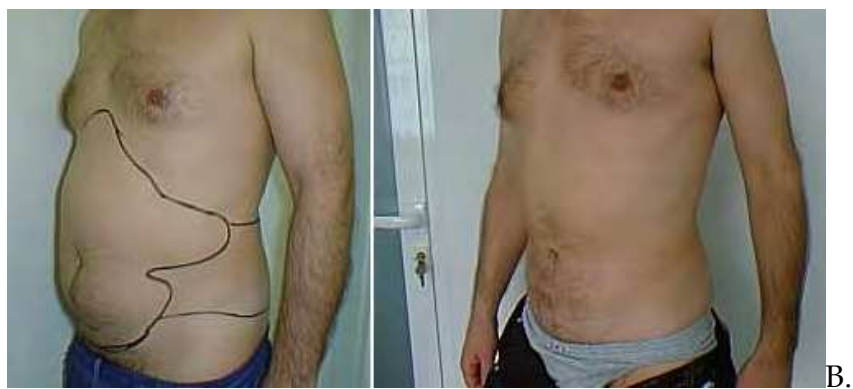

Fig. 6. A. Before, B. Result after 4 months after abdomen and flanks UAL. Loss of fat all around the body - visible loss of volume in the upper arm.

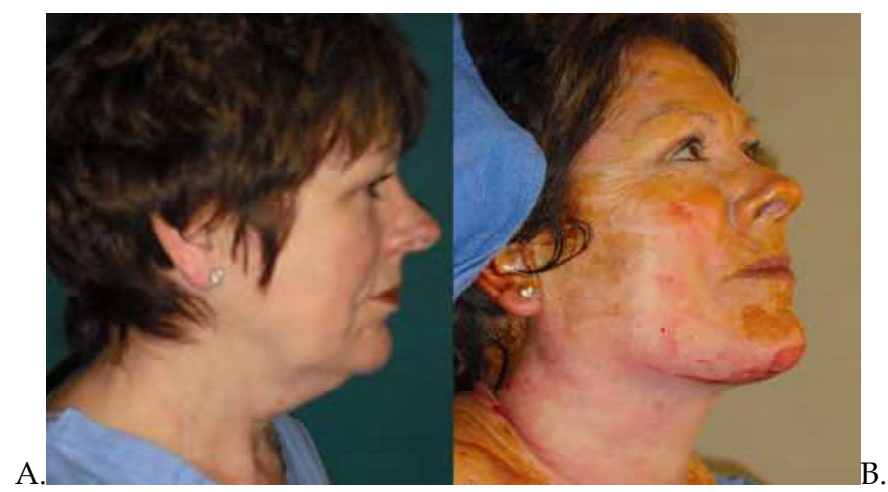

Fig. 7. A. Before, B. At the end of the surgery, the skin still not cleaned from blood and brown colored Braunol. Immediate result after UAL of the lower face and neck - double chin. Immediate result of tightening of the skin. 

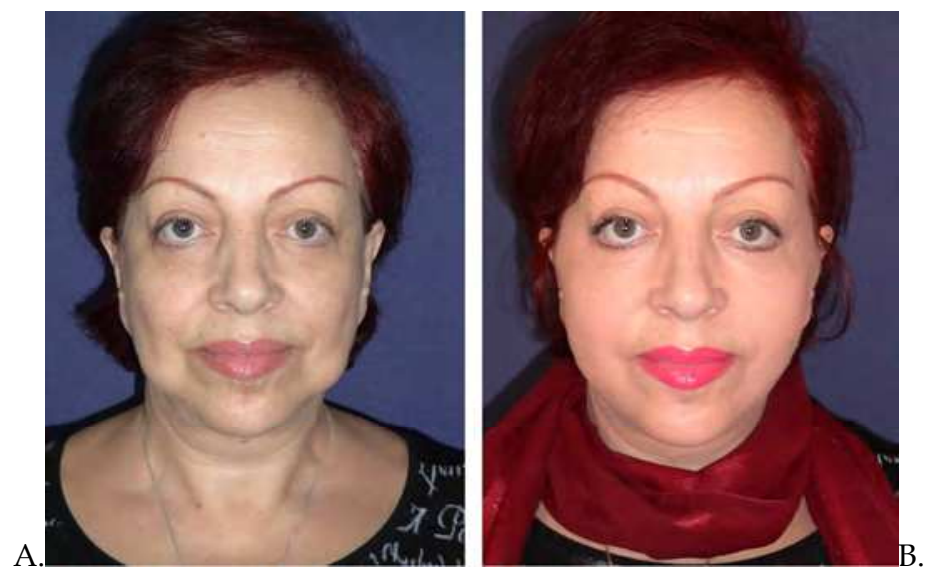

Fig. 8. A. Before, B. Result after cheek UAL. Change from square face into oval. The beauty triangle is achieved.

Optimally, patients should wear these $24 \mathrm{~h} / \mathrm{d}$ for approximately 4 to 6 weeks (depending on summer or winter times and on flabbiness of the skin and tissue). In our geographic area compression will be advised for about a month in summer time, and for a month and a half in wintertime. It will reduce swelling and results will be visible more quickly.

Patients are advised to walk as soon as possible after surgery! Exercising the treated areas should be avoided for about a month after the surgery. Patients are free to fulfill their daily duties, and work after 2-3 days. By exercising regularly and eating a healthy diet, patients will help maintain their new shape.

The treated areas appear to be swollen, but volumes are visibly reduced even on the first day post op (Fig. 1, 2, 7). Swelling augments in the first 7-10 days, and start receding in few weeks when the patients start noticing reduction of dress sizes.

\section{Results and complications}

Following risks in ultrasonic liposuction have not been observed in our cases:

1. No overheating and elevated temperature of targeted fatty tissue was observed. Temperature measured on the surface of the ultrasonic probe and on the surface of the skin was below 37 degrees Cs.

2. No skin necrosis or burns were observed in all cases.

3. No injury to peripheral nerves was found with UAL. Our patients' base appear to have no incidence of prolonged numbness consistent with injury to sensory nerves.

4. Any liposuction method can cause seroma. Seromas can persist for weeks or months if not treated. In our experience the strict daily patient follow up in the first 7 to 10 days after UAL and daily opening of the skin perforations has allowed us to minimize cases of seromas. Only in 3 cases ( 2 males and 1 female) we discovered one side seroma in the flanks that needed drainage for 2 days covered by antibiotic. The seromas were treated with suction through the operation incision using an infiltration cannula and healed in 4 days. The seromas were found deep in this area. Only once we were forced to use drainage for 2 days. 
5. Due to our no sutures and good drainage technique, our patients experienced no hematomas, minimal ecchymoses and bruising.

6. Only one unilateral infection of the right inner knee wound was observed after the third day post op and was treated with widening of the wound from $2 \mathrm{~mm}$ into 5-6 mm, with the tip of a "mosquito" instrument for a daily drainage and daily change of bandages. The infection resolved in few days.

\section{Discussion}

In our experience, Ultrasound-assisted liposculpture (UAL) presents important advantages when compared to traditional liposuction we used before 1994. UAL, allowed us to deliver good aesthetic sculpting and contouring results with preservation of connective, vascular and lymphatic structures, low blood loss and minimal bruising, significant skin retraction capability and weight loss to normal in the first six months (Fig.5, 6, 7, 8), and shortened downtime. All surgeries were done as outpatient.

Highly satisfactory aesthetic results and tiny inconspicuous scars have led us to utilize UAL even in cases of highly pretentious patients like models (Fig. 3). The change of the inner knee fat form and position, visible relative leg elongation and beautification became one of the most requested procedures of UAL in our practice.

The excellent results supported new indications and future developments of "high definition" techniques.

In our experience the UAL has given the possibility to perfect our technique and results.

\section{Conclusion}

This study confirms other author's conclusions that UAL is an effective and safe ambulatory treatment technique in experienced hands when attention is given to proper regulations for application of ultrasound energy [20,40].

The advantages of UAL are decreased bruising, reduced blood loss, overall faster healing, short downtime, and reduction in post-operative discomfort.

We have often used UAL as a "fine-tuning" to treat liposuction irregularities in secondary cases, since it allows for more precision. Using the ultrasound selection of fat cells, we can affect only the irregular fat collections and the superficial subdermal fat layer will be preserved.

UAL increases the safety and minimizes risks because of the reduced trauma and minimized amount of blood removed through UAL. Ultrasonic assisted liposuction is intended to create improved body contouring and harmony. It is safer technique for removing larger amounts of fat compared to other techniques or standard liposuction. Ultrasound action after surgery causes some weight loss all over the body with skin tightening that get noticed in the first 6 months, with remarkable tightening at the end of 18 months. One of the most important advantages of our method is the smooth result.

We believe that UAL is a safe, effective, and easily acceptable procedure for body contouring[18,, 20, 26-28].

\section{References}

[1] Fischer, A, Fischer GM, First surgical treatment for modeling body's cellulite with three $5 \mathrm{~mm}$. incisions. Bulletin of the International Academy of Cosmetic Surgery, September, 1976 
[2] Fisher A, Fisher GM: Revised technique for cellulitis fat reduction in riding breeches deformity. Bull lnt Acad Cosmet Surg 1977; 2:

[3] Klein JA. The tumescent technique for liposuction surgery. J Am Acad Cosmetic Surg 4:263-267,1987.

[4] Klein JA. Anesthesia for liposuction in dermatologic surgery. J Derm Surg Oncol 14:11 24- 1132,1988.

[5] Stewart JH, Cole GW, Klein JA. Neutralized lidocaine with epinephrine for local anesthesia. J Dermatol Surg Oncol 15:1081-1083,1989.

[6] Klein JA. Tumescent technique for regional anesthesia permits lidocaine doses of 35 $\mathrm{mg} / \mathrm{kg}$ for liposuction. J Derm Surg Oncol 16:248-263,1990.

[7] Scuderi N, De Vita R, D'Andrea F. Nouve prospettive nella liposuzione: La lipoemulsificazione. G Chir. 1987;2:1-10.

[8] Zocchi M: New perspective in lipoplasty: The ultrasonic assisted lipectomy (U.A.L.). Presented at the Congress of the French Society of Aesthetic Surgery, Paris, May 1988.

[9] Illouz YG: Body contouring by lipolysis. A 5-year experience with over 3,000 cases. Plast Beconstr Surg 1983; 72:591.

[10] Illouz YG: Surgical remodeling of the silhouette by aspiration lipolysis or se- lective lipectomy. Aesthetic Plast Surg 1985; 9:7.

[11] Fournier P: Liposculpture - Ma Technique. Paris, Arnette, 1989.

[12] Kesselring U, Meyer R: A suction curette for removal of excessive local deposits of subcutaneous fat. Plast Beconstr Surg 1978; 62:305.

[13] Agris J: Suction Assisted Lipectomy: A Clinical Atlas. Houston, Eclectic Pub- lishing, 1983.

[14] Avelar J, Illouz YG: Lipoaspiracao, ed 1. Sao Paulo, Editoria Hipocrates, 1986.

[15] Grazer FM: Suction-assisted lipectomy, suction lipectomy, lipolysis, and li- pexeresis. Plast Beconstr Surg 1983; 72:620.

[16] Kucera IJ, Lambert TJ, Klein JA, et al. Liposuction: contemporary issues for the anesthesiologist. J Clin Anesth. 2006;18(5).

[17] Pinto et al. Liposuction and VASER. Ibid, 108-110

[18] Baker ML, Dalrymple GV: Biological effects of diagnostic ultrasound. Badi- ology 1978; 126:479.

[19] Bartoletti, C.A., Ceccarelli, M., About the Use of Ultrasound at $3 \mathrm{MHz}$ in the Treatment of Localized Adiposity, The Aesthetic Medicine, 1990, No. 1

[20] Baxter, RA. Histologic Effects of Ultrasound-assisted Lipoplasty Aesthetic Surgery Journal March 1999 , 19: 2: 109-114, doi:10.1053/aq.1999.v19.97391

[21] Bartoletti, C.A., Ceccarelli, M., Pignatelli, V., Hydrolipoclasis Ultrasound in the Treatment of Localized Fat Excess: a Modification of the Protocol and Further Evaluation, The Aesthetic Medicine, 1995, No. 2

[22] Apfelberg DB, Rosenthal S, Hunstad JP at al. Progress report on multicenter study of laser-assisted liposuction, , Aesthetic Plastic Surgery, Volume 18, Number 3, 1994 ,Springer New York

[23] Bartoletti, C.A., Ceccarelli, M., Localized Adiposity and Ultrasonic Hydrolipoclasis, The Aesthetic Medicine, 1992, No. 2 
[24] Ceccarelli, M., Chimenti, S., Colantonio, A., Santarelli Marino, AR., Magnetic Resonance Imaging in Monitoring the Treatment of Lipomas with Ultrasonic Hydrolipoclasis, The Aesthetic Medicine, 1994, No. 2

[25] Ceccarelli M. The Hydrolipoclasis Ultrasound, The Aesthetic Medicine, 1997, No. 2

[26] Zocchi M: La liposculpture aux ultra-sons. Actes du Congres d'hiver de la Societe Vran g aise de Chirurgie Esthetique, Paris, Nov 1990

[27] Zocchi M: Liposcultura Ultrasonica. Torino, Italy, Edizioni Scienti6che Cor- tina, 1992.

[28] Zocchi M: Ultrasonic liposculpturing. Aesthetic Plast Surg 1992; 16: 287 - 298.Mark Laurence Jewell. Lipoplasty. In: M. Eisenmann-Klein, Constance Neuhann-Lorenz, eds. Innovations in Plastic and Aesthetic Surgery. Springer, Berlin Germany; 2006:439-444

[29] Haeck, P.C.; Swanson, J.A.; Iverson, R.E; Schechter, L.S.; Singer, R.; Bob Basu, C.; Damitz, L.A.; Glasberg, S.B.; Glassman, L.S.; McGuire, M.F. \& the ASPS Patient Safety Committee (2009). Evidence-Based Patient Safety Advisory: Patient Selection and Procedures in Ambulatory Surgery. Plastic and Reconstructive Surgery, Vol. 124, No. 4S, (October 2009), pp. (6S-27S).

[30] Gasparotti M: Superficial liposuction for flaccid skin patients. Presented at the International Symposium on Recent Advances in Plastic Surgery, Sao Paulo, Brazil, March 28 - 30, 1990, p 443.

[31] Gasperoni C, Salgarello M, Emiliozzi P, et al: Subdermal liposuction. Aesthetic Plast Surg 1990; 14:137 - 142.

[32] Gasparotti M: Superficial liposuction: A new application of the technique for aged and flaccid skin. Aesthetic Plast Surg 1992; 16:141 - 153

[33] Baxter RA, Histologic Effects of Ultrasound-assisted Lipoplasty Aesthetic Surgery Journal March 1999 , 19: 2: 109-114, doi:10.1053/aq.1999.v19.97391

[34] Regnault P: Basic principles and indications of liposuction, in Regnault P, Daniel RK ( eds): Aesthetic P 1 astic Surgery. Boston, Little, Brown, 1984, pp 679 - 692.

[35] Teimourian B: Suction Lipectomy and Body Sculpturing. St Louis, Mosby, 1987.

[36] Heymans O, Castus P, Grandjean FX, Van Zele D. Liposuction: review of the techniques, innovations and applications. Acta Chir Belg. Nov-Dec 2006;106(6):64753.

[37] Schruddle J: Lipexeresis (liposuction) for body contouring. Clin Plast Surg 1984; 11:445.

[38] Pitman GH, Teimourian B: Suction lipeetomy: Complications and results by survey. Plast Reconstr Surg 1985; 76:65 - 72.

[39] Bruno, G, Amadei F, Abbiati G., Aesthetic Plastic Surgery, 1998, Volume 22, Number 6, Pages 401-403

[40] Gingrass MK, Kenkel JM. Comparing ultrasound-assisted lipoplasty with suctionassisted lipoplasty. Institute for Aesthetic and Reconstructive Surgery, Nashville, Tennessee, USA

[41] Serdev, N. Leg beautification and elongation using ultrasonic liposculpture, Int J Cosm Surg. 2009, Volume 9, Number 1, Pages: 1-84

[42] Serdev, N. Body beautification, straight and elongated legs using UAL, Int J Cosm Surg. 2010, Volume 10, Number 3, 1

[43] Ross, R.M. \& Johnson, G.W. Fat Embolism After Liposuction. Chest, Vol. 93, June, 1988, 1294-1295 
[44] Grazer, F.M. \& de Jong, R.H. Fatal outcomes from liposuction: Census survey of cosmetic surgeons. Plastic and Reconstructive Surgery 105:436

[45] Illouz YG. 2006. Complications of liposuction. Clin Plast Surg. Jan;33(1):129-63

[46] Fodor, PB. Watson, J. Personal Experience with Ultrasound-Assisted Lipoplasty: A Pilot Study Comparing Ultrasound-Assisted Lipoplasty with Traditional Lipoplasty, Plastic \& Reconstructive Surgery: April 1998 - Volume 101 - Issue 4 - pp 1103-1116

[47] Gottlieb, S. (2004). "Liposuction does not achieve metabolic benefits of weight loss". BMJ 328 (7454): 1457.

[48] Rohrich RJ, Ha RY, Kenkel JM, Adams WP Jr. Classification and management of gynecomastia: defining the role of ultrasound-assisted liposuction. Plast Reconstr Surg. Feb 2003;111(2):909-23; discussion 924-5.

[49] Góes JC, Landecker A. Ultrasound-assisted lipoplasty (UAL) in breast surgery. Aesthetic Plast Surg. 2002 Jan-Feb;26(1):1-9.

[50] Park S. Very superficial ultrasound-assisted lipoplasty for the treatment of axillary osmidrosis. Aesthetic Plast Surg. 2000 Jul-Aug;24(4):275-9.

[51] Lawrence N, Coleman WP 3rd. Ultrasonic-assisted liposuction. Internal and external. Dermatol Clin. Oct 1999;17(4):761-71.

[52] Lawrence N, Cox SE. The efficacy of external ultrasound-assisted liposuction: a randomized controlled trial. Dermatol Surg. Apr 2000;26(4):329-32.

[53] Flynn TC, Coleman WP III, Field LM et al. History of liposuction, Dermatol Surg. 2000; 26:515-520 


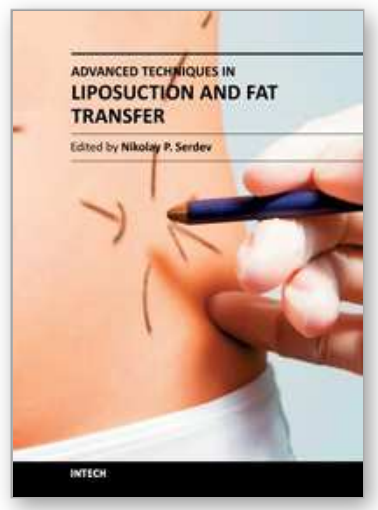

\author{
Advanced Techniques in Liposuction and Fat Transfer \\ Edited by Prof. Nlkolay Serdev
}

ISBN 978-953-307-668-3

Hard cover, 230 pages

Publisher InTech

Published online 12, September, 2011

Published in print edition September, 2011

Liposuction is the first cosmetic procedure to change beutification surgery from open extensive excision surgery into a more atraumatic closed one. It gave rise to the modern understanding of minimally scarring and minimally invasive surgery and changed the understanding and preferences of both patients and doctors. It also became the most common procedure in cosmetic surgery world-wide, practiced by an increased number of physicians from various specialties. The techniques of fat grafting, closely bound with liposuction, have found widespread application and fat stem cells seem to be changing the future of many areas in medicine. Turning the pages, the reader will find a lot of information about advances, tips and tricks, as well as important milestones in the development of the different methods available, such as classic, power, ultrasound, laser and radio-frequency assisted liposuction etc. Most useful anesthesia techniques are described and discussed, and guidelines have been established for medical indications. Special attention is paid to good patient selection, complications and risks.

\title{
How to reference
}

In order to correctly reference this scholarly work, feel free to copy and paste the following:

Nikolay P. Serdev (2011). Ultrasound Assisted Liposculpture - UAL: A Simplified Safe Body Sculpturing and Aesthetic Beautification Technique, Advanced Techniques in Liposuction and Fat Transfer, Prof. Nlkolay Serdev (Ed.), ISBN: 978-953-307-668-3, InTech, Available from: http://www.intechopen.com/books/advancedtechniques-in-liposuction-and-fat-transfer/ultrasound-assisted-liposculpture-ual-a-simplified-safe-bodysculpturing-and-aesthetic-beautificatio

\section{INTECH}

open science | open minds

\section{InTech Europe}

University Campus STeP Ri

Slavka Krautzeka 83/A

51000 Rijeka, Croatia

Phone: +385 (51) 770447

Fax: +385 (51) 686166

www.intechopen.com

\section{InTech China}

Unit 405, Office Block, Hotel Equatorial Shanghai

No.65, Yan An Road (West), Shanghai, 200040, China 中国上海市延安西路65号上海国际贵都大饭店办公楼405单元

Phone: +86-21-62489820

Fax: +86-21-62489821 
(C) 2011 The Author(s). Licensee IntechOpen. This chapter is distributed under the terms of the Creative Commons Attribution-NonCommercialShareAlike-3.0 License, which permits use, distribution and reproduction for non-commercial purposes, provided the original is properly cited and derivative works building on this content are distributed under the same license. 